Diminution des molécules élaborées. - Dans un lait qui s'écarte de la normale pour devenir de plus en plus malade, nous verrons donc diminuer progressivement, et d'autant plus que la lésion de la glande est plus accentuée, le quantum des molécules élaborées dont nous venons de parler tout à l'heure.

Augmentation des molécules non élaborées. - En même temps, nous verrons s'élever le taux des molécules non élaborées qui entrent également dans la composition du lait, mais sans donner à celle-ci une caractéristique quelconque.

De cette observation générale, nous pouvons déjà conclure que le trouble apporté dans le fonctionnement physiologique de la cellule mammaire doit être relativement indépendant de l'agent microbien qui intervient. Quelle que soit l'espèce microbienne qui déclenche le processus infectieux, du moment qu'elle possède des propriétés phlogogènes, l'unicité de l'évolution des altérations chimiques de la sécrétion lactée au cours des mammites répond à l'observation générale qui vient d'être faite : à savoir que ce sont les molécules élaborées qui vont disparaître, laissant la place aux molécules non élaborées. La cellule mammaire réagit toujours dans le même sens; seulement, elle le fait plus ou moins énergiquement.

(A suivre.)

\title{
REVUE
}

\section{LES LEVAINS LACTIQUES EN LAITERIE ET LES ORGANISMES QU'ON Y TROUVE (1)}

\author{
par \\ C. D. KELLY
}

Station expérimentale agricole de l'Etat de New-York, Geneva (N. Y.).

Le phénomène de l'acidification du lait et le rôle qu'il joue dans l'industrie laitière présentent depuis longtemps un grand intérêt, aussi bien au point de vue pratique qu'au point de vue scientifique.

Le laitier a utilisé ce phénomène dans la production du beurre et du fromage dans le but d'améliorer ces produits. Il n'est pas douteux que le lait ait été employé dès l'antiquité à l'état liquide ; mais comme il s'acidifie rapidement, on a recherché les façons diverses de l'utiliser néanmoins comme aliment. Dans quelques cas le lait était consommé, d'abord, à l'état fermenté, mais la plus grande

(1) Traduit de Milk Plant Monthly (novembre et décembre 1931). Nous avons plaisir à reproduire in extenso, cette revue très claire d'une question si importante dans l'industrie du beurre et des fromages. (R.) 
quantité l'était soit sous forme de fromage soit sous forme de beurre. C'est probablement à la nécessité qu’est dû l'emploi de la crème mûrie pour la fabrication du beurre : la séparation spontanée de la crème étant un processus lent, il en est résulté fatalement que la crème à employer était acide avant d'être barattée. Quand la séparation de la crème fut rapidement rendue possible avee les machines centrifuges, l'emploi de la crème acide ou mûre continua parce qu'une saveur agréable se dégageait dans le beurre parfumé $q u$ 'on en obtenait. Depuis longtemps, les laitiers savaient que le lait et la crème de certaines sources faisaient le meilleur beurre, et les crèmes acides d'un très bon parfum provenant de ces sources étaient employées pour mûrir les autres crèmes avant le barattage du beurre. Nous avons donc ici le premier levain naturel (starter, comme on dit en anglais) qui était ensemencé de jour en jour dans la crème à travailler. En 1866, FLINT [1] donne des instructions pour l'emploi d'un tel levain : "Lorsque le lait a été amené de la cour ou de l'étable, il doit être versé immédiatement dans des pots où l'on a mis un peu de lait acide dont la crème a été enlevée, la quantité variant d'une cuillère à potage à une demi-tasse à thé suivant l'état de la température. "

Pour la fabrication du fromage, le développement de l'emploi des levains a suivi la même voie que pour le beurre. Dans beaucoup de eas, on laissait le lait surir normalement, les processus de la fabrication commençant alors que l'acide se développait. Des levains étaient ajoutés par certains fromagers, sous une forme de sérum acide provenant de la fabrication du jour précédent ou en utilisant du lait mis à part que l'on avait laissé s'acidifier. En Angleterre, où une grande proportion du fromage est faite dans les fermes, la pratique dans le passé était d'ajouter le lait du soir au lait $\mathrm{du}$ lendemain matin et l'on estimait que la croissance des bactéries dans le premier était suffisante pour développer une acidité favorable dans la fabrication du fromage. Plus récemment, des levains commerciaux ont été très utilisés par les fromagers anglais.

développement du Parfum et de la saveur. - Dans les deux dernières décades du $\mathrm{XIX}^{\mathrm{e}}$ siècle, on prit grand intérêt au développement d'un arome particulier du beurre. STORCH, à Copenhague, fut le premier à s'intéresser à ce sujet. Le travail de HANSEN [2], qui faisait déjà usage de cultures pures de levures dans la brasserie, semble l'avoir pénétré de l'idée d'assembler des bactéries qui donneraient un bon arome et une bonne saveur et de les utiliser comme levain dans la fabrication du beurre. STORCH publia son premier travail à ce sujet en 1890 [3]-[4].

Le premier, du babeurre il isola des organismes qui n'étaient pas 
très satisfaisants, car ils ne donnaient pas l'arome et la saveur requis bien qu'ils fussent de bons producteurs d'acides. Plus tard, il obtint de meilleurs résultats en isolant des cultures de crèmes bien mûries, et l'une de ces cultures (souche 18), qui produisait un arome désirable ainsi qu'une acidité suffisante, était très connue. Les cultures de STorch furent utilisées avec succès comme levain dans la fabrication du beurre. En 1890, à Kiel, WEIGMANN [5] isola également des bactéries qu'il employa comme levains. Ils produisaient un arome et une saveur agréables et furent employés dans les laiteries de l'Allemagne du Nord pendant plusieurs années.

Sur ce continent, à Storrs, à la Station expérimentale du Connecticut, Conn publia en 1889 et au cours des années suivantes les résultats de ses très intéressantes expériences sur la maturation de la crème. Tandis qu'il peut isoler de bons producteurs d'acides, l'arome et la saveur désirés [6] ne se développent pas; aussi émet-il l'opinion qu'un bon levain ne saurait être obtenu avec une seule espèce de bactéries. A l'Exposition internationale de Chicago de 1893, EsTEN, travaillant avec CoNN, isola un certain nombre d'organismes d'un échantillon de lait provenant de l'Uruguay qui n'avait pas été soigneusement stérilisé et qui commençait à devenir amer. Parmi les souches obtenues, CoNn trouva une eulture ( $n^{0} 41$ ) [7] qui fut largement éprouvée au cours des années suivantes comme levain, bien que très discutée. Quoique dans des expériences préliminaires il ait été décrit comme produisant peu d'acide mais développant un arome et une saveur désirables dans le beurre, il ne donna aucun résultat heureux quand son emploi passa dans l'industrie.

LEVAINS COMMERCIAUX. - Des levains commerciaux semblent avoir été mis sur le marché d'abord en Danemark en 1890 par Bla Uenfeld et TVEDe [8]. Rapidement, d'autres pays suivirent, et depuis bien des années, ils ont été essayés en Amérique. En 1895, Robertson [9], au Canada, compare un levain qu'il a obtenu luimême avec deux autres qu'il avait reçus du Danemark, l'un de Chr. Hansen, et l'autre de Zofmman. Conn [7] dans le rapport annuel de la Station de Storrs (1895) mentionne avoir utilisé un levain de la Compagnie laitière Carl Hansen. En 1897, l'emploi des levains lactiques purs semble avoir pris une grande extension au Danemark, puisque 802 crémeries sur 866 employaient des cultures pures, les 64 autres employant la méthode d'acidification naturelle [10]. CoNn [11], en 1899, dans un rapport sur la bactériologie laitière en Europe montre qu'au Danemark il y avait pour la vente, à ce moment, différents levains dont la plupart étaient des cultures pures, mais qu'il y en avait cependant qui étaient des mélanges de bactéries et que l'un d'entre eux contenait dix à douze espèces diffé- 
rentes. Tandis que quelques-uns de ces mélanges étaient artificiels, d'autres étaient naturels. Il discute ensuite l'emploi des cultures pures dans la fabrication de la margarine et du fromage et bien qu'il mentionne qu'une laiterie vendait des cultures pures pour la fabrication des fromages, il ne dit pas s'il s'agissait de cultures de ferments lactiques ou de cultures de moisissures comme le réclame l'ensemencement des fromages à veines bleues.

Durant les 17 années suivantes un grand progrès fut fait dans l'emploi des levains commerciaux et autres qui furent utilisés, non seulement pour la maturation de la crème destinée à faire du beurre, mais aussi dans l'industrie de la margarine et dans la fabrication du fromage; en Amérique du Nord leur emploi était très répandu, tout au moins dans la fabrication des boissons lactées acides.

Durant cette période peu de travaux fondamentaux furent publiés et la majorité des publications sur les levains semble avoir été d'esprit pratique [12].

Depuis 1914 l'intérêt s'attacha de nouveau aux levains notamment en ce qui concerne l'étude de leur flore bactérienne. Une importante discussion sur les levains fut soulevée au Congrès international de Laiterie à Berne la même année [13].

\section{LES TRAVAUX ANTÉRIEURS SUR LES ORGANISMIES POUVANT SERVIR}

DE LeVains. - Avec le développement de la bactériologie systématique, une grande confusion survint à cause des descriptions incomplètes et des fautes de nomenclature. Le dernier travail consista à identifier avec beaucoup plus de sûreté qu'auparavant les organismes qu'on estimait devoir être associés dans les levains et les laits acides; du fait de la confusion existant jusqu'alors, le problème impliquait pour commencer une étude de terminologie.

Attendu que le lait acide fut en réalité le premier levain, l'attention est appelée tout d'abord dans cette direction. PASTEUR, en 1857 [14], s'était occupé lui-même de ce problème ; il avait trouvé des organismes qui causaient l'acidification du lait et il les avait cultivés dans du, bouillon sucré. De sa description, cependant, il semble qu'il a eu affaire à des organismes du groupe Coli plutôt qu'aux vraies bactéries lactiques, ainsi qu'il résulte de la formation de gaz carbonique et d'hydrogène qui ont été produits par la culture de ces organismes dans le bouillon sucré.

Lister, en 1873 [15], continua les travaux de PASteur. Il étudia l'acidification du lait et fut le premier à isoler et à décrire un véritable organisme lactique qu'il appela Bacterium lactis. Plus tard, Lehman, WoLfF, KRUse [16] et d'autres auteurs ne voulurent pas accepter ce nom parce qu'ils trouvaient que la description de LISTER 
n'était pas suffisante pour identifier l'organisme trouvé par celui-ci, comme celui qui causait l'acidification normale du lait. Cependant, LISTER a continué ses recherches à la température la plus favorable pour la culture de l'organisme acidifiant du lait, soit $21^{\circ} \mathrm{C}$, et il a ajouté le fait que les organismes qu'il a isolés font cailler le lait en donnant un coagulum uni, solide et onctueux. Il a complété le tout par une description de l'organisme qu'il dit avoir trouvé sous la forme de courts bâtonnets associés par paires, si bien que tout porte à croire qu'il avait obtenu la forme véritable.

Que l'acidification du lait puisse être causée par plus d'un organisme, cela a été affirmé très rapidement par de nombreux chercheurs. HuEPPE, en 1884 [17], suivi par MARPMANN, en 1886 [18], et GrotenFELDT, en 1889 [19], trouva dans le lait un certain nombre de bactéries capables de l'acidifier. HuEPPE [17] employa la température d'incubation à $37^{\circ} \mathrm{C}$, , et il isola un organisme qui fut, en particulier, considéré plus tard par beaucoup comme celui qui est responsable de l'acidification du lait. Son travail fut, dans les années suivantes, la cause de beaucoup de confusion dans la littérature. Cet organisme que HUEPPE appelait Milchsäurebacterium fut également appelé par ZoPF [27] Bacillus acidi lactici. Il fut examiné quelque temps après par Grotenfendt [19], qui, avec l'aide d'une meilleure technique, fut capable de démontrer qu'il ne s'agissait pas de l'organisme responsable de l'acidification normale du lait, mais qu'il appartenait au groupe du Coli. GrotenfeLdT, également, au même moment (1889) [19], décrit un streptocoque à longue chaîne trouvé dans le lait, qu'il appela Streptococcus acidi lactici, nom qui a été employé par plusieurs bactériologistes comme celui de l'organisme du lait acide. En dépit du fait que Grotenfeld a montré que l'organisme décrit par HuEPPE était du groupe Coli, le nom donné par ZoPF à l'organisme isolé par HuEPPE continue à paraître dans la littérature. Conn employa le nom Bacterium acidi lactici d'une façon tout à fait large, comme étant associé avec la crème acide et les levains, bien qu'il n'établît point que les organismes qu'il isola n'étaient pas identiques avec celui que HuEPPE avait décrit.

LE TRAVAIL MODERNE SUR LES ORGANISMES DES LEVAINS. En 1895, GüNTHER et THIerfelder [21], en étudiant l'acidification du lait, établirent que les organismes qu'ils trouvèrent ressemblaient beaucoup plus à la souche décrite par Lister que ceux décrits par HUEPPE, mais ils continuèrent néanmoins à utiliser le nom donné antérieurement par HUEPPE (Bacterium acidi lactici). Lehman et NeUmanN, dans les années suivantes (1896) [22], donnèrent le nom de Bacterium güntheri à l'espèce décrite par Günther et Thierfelder, nom qui a été très employé en Alle- 
magne, Leichmann, la même année, en 1896 [23], arriva également à la conclusion que les organismes qu'il trouvait dans le lait acide s'accordaient bien mieux avec celui de Lister qu'avec celui de HuEpPE. Au lieu d'employer le nom donné par Lister, il proposa le nom Bacterium lactis acidi, nom qui a été très employé en Amérique pour désigner l'organisme du lait acide. LeICHMANN établit au même moment que tandis que le Bacterium lactis acidi forme de l'acide lactique droit, le lait qui s'acidifie naturellement montre de l'acide lactique inactif. KozaI, en 1899 [24], mit cette question au clair quand il démontra que l'acide du lait acidifié à $37^{\circ} \mathrm{C}$. était du type inactif, tandis que celui acidifié à $21^{\circ} \mathrm{C}$. était de l'acide lactique droit. Il établit, également, que l'organisme de HuEPPE poussait mieux à $37^{\circ} \mathrm{C}$., tandis que celui décrit par LeICHMANN (Bacterium lactis acidi) poussait mieux à $21^{\circ} \mathrm{C}$. Il ajouta à la confusion par la dénomination de cet organisme, qu'il proposa d'appeler Bacterium acidi paralactici.

BEIJERINCK [25], en 1901, estimant que des organismes ronds ou ovales ne devaient pas être placés dans un genre caractérisé par des formes en bâtonnets, proposa le nom générique Lactococcus pour les organismes rappelés plus haut. KRUSE [26], en 1903, établit le fait que l'organisme producteur d'acide lactique ressemblait beaucoup à certaines espèces du genre Streptococcus et il lui donna le nom Streptococcus lacticus. Hölling, en 1904 [27], en faisant passer ses souches au travers d'animaux de laboratoire, mit en évidence l'idée de Kruse. Heineman, en 1906 et 1907 [28], apporta une preuve concluante que l'organisme acidifiant le lait présente une ressemblance marquée morphologique avec le Streptococcus pyogenes, en le faisant passer à travers des animaux ou en le cultivant dans un milieu lactosé et le lait. Ces recherches de HEINEMAN convainquirent les bactériologistes que cet organisme appartenait au genre Streptococcus. LöHNIs [29], en proposant que cet organisme fût placé dans le genre que Kruse avait suggéré, fit beaucoup pour aplanir la confusion, et le nom Streptococcus lactis a été largement accepté (1).

ORLA-JENSEn, de Copenhague, en 1919 [30], après avoir étudié pendant de longues années les organismes lactiques, divisa le groupe des bactéries considérées généralement comme causant l'acidification du lait en plusieurs espèces différentes. Les deux qui sont le plus en rapport avec les levains sont Streptococcus lactis et Streptococcus cremoris. Il a utilisé le nom Steptococcus lactis pour le diplo-

(1) Psur une liste complète des synonymes de Streptococcus lactis Löhnis (Lister), voir Ayers, Johnson et Mudge : Journal Infec. Dis. 34, 1924, pp. 29-48; R. S. BReed : Newer Knowledge of Bacteriology and Immunology (Edité par Jordan et Falk. U. of Chicago Press; 1929). 
coque décrit d'abord par.LISTER et qui prédomine dans le lait acide, et il a donné le nom de Streptococcus cremoris à la culture de STORCH [18], qui est un organisme produisant un arome agréable et cultivant dans le lait en longues chaînes de Cocci. Le Streptococcus cremoris, outre qu'il forme de longues chaînes et produit un arome agréable dans le lait, se montre lui-même mieux adapté à cultiver dans le lait que le Streptococcus lactis. L'action de ces deux organismes sur certains des hydrates de carbone sert également à les distinguer l'un de l'autre. Le Streptococcus cremoris montre une préférence plus grande pour le lactose que le Streptococcus lactis, et il n'attaque pas le maltose et la dextrine, qui, tous deux, sont attaqués par le Streptococcus lactis.

Pendant beaucoup d'années, l'idée avait prévalu qu'un bon levain pouvait consister en une seule espèce de bactéries lactiques. Mais dès 1889, Conn [6] suggéra que plusieurs espèces étaient nécessaires pour former un bon levain, et plus tard, en 1908, WEIGMANN [31], après plusieurs années d'expériences sur les levains, en vint à la même opinion. Il établit que les cultures pures pour la fabrication du beurre doivent contenir des ferments du type Streptococcus lacticus et du type aromatique, et aussi que l'arome spécifique est produit par plusieurs espèces bactériennes. STORCH, peu avant sa mort, était de la même opinion, et dans son dernier travail, publié en 1919 [32], il décrivit certaines bactéries produisant de l'arome mais peu d'acide, qu'il considérait comme les organismes causant le parfum du beurre quand ils poussaient avec les autres organismes du levain plus particulièrement producteurs d'acide.

Dans un appendice à son genre Streptococcus, ORLA-JENSEN [30] a placé certains Cocci isolés des levains, qu'il considérait comme étant semblables à certaines bactéries que BowkHоUr [33] décrivit en 1917 comme étant responsables de l'arome de la crème acide. Ces organismes développent très peu d'acide, mais ils sont eapables de produire l'arome désiré du beurre quand ils poussent dans la crème.

Simultanément à la publieation du travail de STORCH et de celui d'ORLA-JENSEN, deux autres travaux parurent sur les bactéries aromatisantes mais peu acidifiantes : l'un de HAMMER et BaIley [34], en Amérique, et l'autre de Bozkhout et DE VRIES, en Hollande [35]. HAMmER et BATLEY isolèrent certaines bactéries des levains qu'ils considérèrent comme étant responsables, en partie du moins, de l'arome du beurre. Ils montrèrent que ces organismes étaient de grands producteurs d'acides volatils et que lorsqu'ils poussaient avec le Bacterium lactis acidi, ils étaient capables de produire une proportion plus grande d'acides volatils, à cause de leur pouvoir de faire fermenter l'acide citrique. Hammer les dé- 
nomma Streptococcus citrovorus et Streptococcus paracitrovorus [36]. Böкночт et DE VRIES cultivent les levains sur gélatine-sérum et vont recueillir les colonies dans le lait. Quelques-unes des souches isolées de cette manière étaient des Cocci qui donnaient l'arome désiré du beurre au lait bien qu'ils ne donnassent que peu ou pas d'acide.

Hammer [37], en 1920, et AxERS et MUdGE, en 1921 [38], montrèrent que l'action associée des bactéries aromatisantes avec le Streptococcus lactis formait de l'acide lactique droit et un peu d'acide inactif, tandis que le Streptococcus lactis, comme aussi le Streptococcus cremoris, formait seulement de l'acide droit. Comme les bactéries aromatisantes sont de pauvres producteurs d'acide, ces chercheurs ne furent pas capables de déterminer le type d'acide lactique formé par elles quand ces organismes poussaient seuls. ORLA-Jensein et ses collaborateurs [39], en 1926, démontrèrent qu'avec l'addition de petites proportions d'un extrait de levure autolysée, ces bactéries étaient capables de former des quantités d'acide laetique comparables à celles que produisent le Streptococcus cremoris et le Streptococcus lactis. Cet acide lactique était trouvé du type lévogyre.

OrLa-Jensen [30] semble, pendant un certain temps, avoir eu l'opinion que ces bactéries aromatisantes étaient des formes affaiblies du Streptococcus cremoris, lequel, pour une raison ou une autre, avait perdu le pouvoir de former de l'acide et avait augmenté celui de produire de l'arome. Cependant du fait que les bactéries aromatisantes forment de l'acide lactique gauche, il a considéré depuis [39] qu'elles relevaient de son genre Betacoccus. Sonoke KNUDSEN et Sormnsen, en 1929 [40], isolèrent également des levains lactiques des cultures de ces bactéries et les placèrent dans le genre Betacoccus C'Orha-Jensen [30] en proposant de les dénommer Betacoccus cremoris; ces espèces ne devraient pas être confondues avec le Streptococcus cremoris. Ces deux chercheurs ont également décrit un organisme qui avait été antérieurement trouvé par P. Arne HANsEN dans le laboratoire d'ORLA-JENSEN, et qui avait été appelé i-bacterium; ce dernier apparaît avoir beaucoup plus de caractéristiques communes avec les organismes du genre Betacoccus, tout en approchant de près les types des organismes Streptococcus en ce qu'ils produisaient de l'acide lactique droit.

HUCKER [41] arriva à cette conclusion que les bactéries aromatisantes décrites par HAMmER et ses collaborateurs ainsi que par ORLA-JENSEN ont certaines caractéristiques communes à d'autres organismes décrits dans la littérature. Hucker et PEDERson [42] ont recueilli du matériel de plusieurs sources et, après avoir isolé et étudié un grand nombre de cultures, ils les ont comparées avec 
certains organismes antérieurement décrits. Ils trouvèrent que les bactéries aromatisantes du beurre avaient des caractéristiques communes avec les Cocci isolés antérieurement des légumes, de la choucroute et du sirop de sucre et ils les ont groupés tous dans un genre pour la dénomination duquel ils employèrent le vieux nom générique Leuconostoc [42] proposé par CIenkowskI en 1878 [43] pour la culture glaireuse de ces organismes isolés de certaines usines. Ils ont reconnu trois espèces : Leuconostoc citrovorus (Hammer) Hucker et Pederson, Leuconostoc mesenteroides Cienkowski, et Leuconostoc dextranicus (Beijerinck) Hucker et Pederson. Ils y introduisent les types qui ne font pas coaguler le lait en produisant du gaz carbonique et de l'acide lactique gauche. Il est intéressant de noter que l'organisme isolé par vON FREUDENREICH du kéfir en 1897 [44] et dénommé Streptococcus kefir par MrguLa en 1900 [45] se place dans ce groupe ainsi que les organismes isolés par BEIJERINCK en 1912 et dénommés Leuconostoc dextranicus [46].

EMPLOI DES LEVAINS DU BEURRE DANS LA FABRICATION DES FROmAGes. - Le rôle joué dans la maturation des fromages par les levains composés de plus d'une souche de bactéries a intéressé nombre de chercheurs. BARTHEL et SADLER, en 1928 [47], comparent l'action des levains de la laiterie avec celle de certaines cultures de bactéries. Bien que les levains de la laiterie ne donnent pas plus d'azote soluble que les cultures pures, ils détachent de plus larges proportions d'azote aminé. Ces auteurs considèrent qu'une action semblable doit se retrouver dans le fromage. Hucker et MaRQUARDT, en 1926 [48], firent des fromages avec les différents types de bactéries des levains et trouvèrent que le Streptococcus paracitrovorus quand on l'ajoute seul au lait pour la fabrication du fromage, ou en conjonction avec des levains commerciaux, paraît avoir une action désirable sur la saveur du fromage de Cheddar obtenu. Le Streptococcus citrovorus et le Streptococcus lactis n'ont aucune influence apparente sur cette saveur.

BESOINS NUTRITIFS DES ORGANISMES DES LEVAINS. - Le lait n'a pas toujours été trouvé être un milieu satisfaisant pour cultiver les levains et ce sujet a été étudié par nombre de chercheurs. LARSON et WhiтЕ, en 1910 [49], proposaient l'emploi de la poudre de lait comme milieu de culture pour les levains, et BouskA, en 1909 [50], fit des essais avec addition de sucre et de neutralisants. En démontrant que les bactéries aromatisantes font fermenter les citrates, HAMMER et ses collaborateurs ajoutèrent de l'acide citrique au lait servant de levain [51]. Templeton et Sommer, en 1929 [52], firent porter leurs investigations sur l'influence de l'acide citrique et du citrate de sodium quand on les ajoute au lait devant servir de milieu 
à la fabrication des levains. Bien que OrLA-Jensen [39] [53] ne plaide pas pour l'addition d'extrait de levure au lait dans la culture des levains, il démontra que la croissance des bactéries aromatisantes est grandement stimulée par l'addition de petites proportions d'extrait de levure. Soncke KNudSen et Sorensen, en 1927 [56], trouvent que certains laits, quand on les emploie pour faire des levains, ne donnent pas de bons résultats, et ils pensent que cela doit être une particularité du lait de certaines vaches. Plus tard, en 1929 [40], SONCKE KNUDSEN et SoRENSEN démontrèrent que certaines variations dans le lait étaient dues à plusieurs causes qui s'accentuaient sous l'action de certaines souches de Betacoccus (Leuconostoc) dans les levains. Ils suggérèrent, comme l'avait fait ORLA-JENSEN en 1926 [39], que l'amélioration de la eulture des levains dans le lait par l'addition d'extrait de levure, peut être due à des vitamines. Ils trouvent que le lait d'un extrait sec faible donne de pauvres résultats pour faire le levain, ce qu'ils attribuent à des variations de l'action-tampon; le lait faiblement tamponné permettrait au Streptococcus cremoris de surpasser le Betacoccus, tandis que les laits mieux tamponnés permettraient aux organismes des levains de pousser ensemble et de produire à la fois l'arome et l'acide désirés. Ils montrent également que certains levains et certaines souches de Streptococcus cremoris ne donnent pas de bons résultats avec le lait traité aseptiquement, mais en donne dans le lait de marché et dans le lait additionné d'extrait de levure ou de lait autolysé.

conclusions. - Durant les quarante années pendant lesquelles les levains ont été étudiés, ils ont été presque universellement adoptés dans la fabrication du beurre et du fromage de haute qualité. La connaissance des bactéries qui interviennent dans l'action des levains 's'est beaucoup augmentée pendant ce temps. Tout d'abord, on trouva des streptocoques producteurs d'acide lactique, mais il y eut beaucoup de confusion quant à leur nom et à leur identification. Ensuite, des bactéries furent trouvées dont l'importance résulte de l'arome très fin qu'elles communiquent au beurre. Un travail récent a démontré que certaines souches productrices d'acide lactique Streptococcus cremoris ne cultivaient pas d'une façon satisfaisante dans le lait de haute qualité. Dans ce travail il a été relevé que le lait destiné à la production d'un levain doit être bien tamponné afin que l'acide produit par le Streptococcus cremoris n'empêche pas la croissance des bactéries aromatisantes. Il semblerait que les bons levains doivent contenir des souches de Streptococcus cremoris (Orla-Jensen) aussi bien que certains types de Leuconostoc (probablement Leuconostoc citrovorus (Hammer) Hucker et Pederson), pour que l'arome désiré du beurre puisse être obtenu. Les autres strep- 
tocoques producteurs d'acide lactique (Streptococcus lactici, etc.) normalement présents dans la erème et le lait peuvent aussi jouer un rôle.

Note spéciale. - Alors que ce travail était à la veille d'être publié, deux travaux traitant des levains ont paru. Le premier, de SonCKE KNUDSEN [57], publié en Angleterre, traite brièvement l'historique des levains, mais plus complètement celui des bactéries et des méthodes de contrôle. Le second, de HANSEN [58], publié au Danemark, traite plus spécialement du rôle joué par OrLAJENSEN et d'autres auteurs danois dans l'histoire des levains.

\section{BIBLIOGRAPHIE.}

[1] Flint, Charles F., 1866. Milch Cows and Dairy Farming. Crosby and Ainsworth, Boston, p. 231.

[2] Klocker, Alb., 1903. Fermentation Organisms. Longmans, Green and Co., London, p. 355-357.

[3] Storch, V., 1890, Nogle Undersogelser over Flodens Syrning. (Studies on the Ripening of Cream). 18de Beretning fra Forsogslaboratoriet. Kgl. Veterinaer og Landbohojskoles Laboratorium for Landokonomiske Forsog. Kobenhavn.

[4] Anonyme, 1890. Untersuchungen über Butterfehler und Säurung des Rahms. Milchzeitung, p. 304-305. Includes a review of Storch's work and two figures showing his Culture 18.

[5] Weigmann, H., 1890. Neue Mitteilungen über Rahmsäuerung mittelst Reinkulturen von-Säurebakterien. Milchzeitung, p. 944-947.

[6] Conn, H. W.,

a) 1889. Bacteria in milk and its products. Storrs (Connecticut) Agr. Exp. Sta. Bull. 4, 1-12.

b) 1891. Ripening of Cream. Storrs (Connecticut) Agr. Exp. Sta. Ann. Rept. for 1890.

c) 1894. Bacteria in the Dairy. Storrs (Connecticut) Agr. Exp. Sta. Ann. Rept. for 1893, p. 43-68.

[7] Conn., H. W.,

a) 1894. The ripening of cream by artificial bacteria cultures. Storrs (Connecticut) Agr. Exp. Sta. Bul. 12.

b) 1895. Bacteria in milk. II. Experiments in ripening cream with Bacillus 41. Storrs (Connecticut) Agr. Exp. Sta. Ann. Rept. for 1894, p. 57-68.

c) 1895. Bacteria in dairy. IX. A year's experience with Bacillus No.41 in general dairying. Storrs (Connecticut) Agr. Exp. Sta. Rept. for 1895, p. $17-40$.

[8] Orla-Jensen, S., 1921. Dairy Bacteriology. Translated by P. S. Arup. .T. \& A. Churchill, London, 1921, p. 108.

[9] Robertson, J. W., 1895. Comparative tests of pure cultures of bacteria. Canadian Exp. Farms. Rpt. for 1894, p. 86-89.

[10] Hansen, Sophus, 1897. Versuche mit Bakterienkulturen für die Rahmsäue rung. Milchzeitung, $\_6$, p. 590 . 
[11] Conn, H. W., 1899. Some pratical applications of Bacteriology in European Dairying. Storrs (Connecticut) Agr. Exp. Ann. Rept. for 1898, p. 67-99.

[12] Mason, J. Christie, 1915. Tests and Comparisons of Commereial lactic starters. Storrs (Connecticut) Agr. Exp. Sta. Bul. 83, p. 112-125.

Stevenson, W., 1909. Report on the results of experiments on the propagation of culture starters in dairying. Wes. of Scot. Agr. Col. Bul. 50 pp. 78-105.

Ross, M. N., 1900. Report of the Bacteriological Department. Ont. Agr. Col. Rept. for 1899 , p. 96.

Campbell, J. R.,

a) 1899. Pure cultures for cheddar cheese making. Trans. High and Agri. Soc, Scot. 5 ser., 11, pp. 205-220.

b) 1899. Pure cultures vs. home-made starters. Dairy 11, No. 124, p. 107, London.

Conn., H. W,, 1900. The ripening of eream. Storrs (Connecticut) Agr. Exp. Sta. Bul. 21.

McKay, G. L., 1901. Starters and flavors: Nat. Cream Butter Makers Ass. Rept., p. 133-140.

Farrington, E. H., et Russell, H. L., 1904. Use of bacterial culture starters in butter making with especial reference to the Conn culture (B41). Wis. Agr. Exp. Sta. Rept. for 1903, pp. 167-176.

Beach, C. L., 1903. Creamery problems. Storrs (Connecticut) Agr. Exp. Sta. Bul. 40, pp. 38-47.

Pernot, E. F., 1905. The perpetuation of pure cultures for butter starters. Oregon Agr. Exp. Sta. Bul. 83, p. 8.

Beau, M., 1905. The struggle against tuberculosis in Denmark, pasteurization and the use of pure cultures in Danish dairies, Ann. Inst. Nat. Agron. 2, Ser., No. 1, p. 25-96.

Bushnell, L. D., et Wright, W. R., 1907. The pratical use of starters. Mich. Agr. Exp. Sta. Bul. 246, pp. 139-151.

Michels, J., 1909. Manufacture and Marketing of cottage cheese, skimmilk, buttermilk and ice cream. North Carolina Agr. Exp. Sta. Bul. 202, p. 5-11.

Melick, C. W., 1909. Buttermaking in Maryland. Maryland Agr. Exp. Sta. Bul. 135, p. 225-284.

Hastings, E. G., 1910. The propagation of pure starters for butter and cheese making. Wisconsin Agr. Exp. Sta. Bul. 181, p. 3-17.

Farrington, E. H., et Hastings, E. G., 1910. The propagation of pure culture starters for butter and cheese making. Wisconsin Agr. Exp. Sta. Circ. Inform. 2, p. 1-4.

Funder, L:, 1913. Experiments with commercial and homemade starters. (Trans. title). Aarsber. Offentl. Foraust. Landb. Framme. III. Statsforaust., p. 687-720.

Brown, C. W., et Peiser, K., 1916. Keeping quality of butter. IV. Cream Ripening and its Influence. Mich. Agr. Exp. Sta. Tech. Bul. 29, p. 7-20.

[13] Reports, 1914. Lactic-acid Bacteria and their utilization in the Dairy Trade. Sixth International Dairy Congress in Berne, Sec. II, Question 4.

[14] Pasteur. L., 1857. Mémoire sur là fermentation appelée lactique. Compt. rend. Acad. des Sci., Paris, 45, 913-916. Ann. de Chim. et Phys. (3e sér.) 52, 404-918, 1858. 
[15] Lister, J.,

a) 1873. A Further Contribution to the Natural History of Bacteria and the Germ Theory of Fermentation Changes. Quart. J. Micr. Sc., 13, 380, 1873. et Collected Papers of Joseph, Baron Lister, Vol. II., p. 309. The Clarendon Press, Oxford, 1909.

b) 1878. On the Nature of Fermentation. Quart. J. Micr. Sc. 18, 177, 1878. et Collected papers of Joseph, Baron Lister. Vol. II, p. 336, The Clarendon Press, Oxford, 1909.

c) 1878. On the Lactic Fermentation and Its Bearing on Pathology. Trans. Path. Soc. London, 29, 425, 1878. et Collected Papers of Joseph, Baron Lister, Vol. II, p. 353. The Clarendon Press, Oxford, 1909.

[16] Kruse, W., 1910. Allgemeine Mikrobiologie, Leipzig, 1910, XV et 1184. Wolff, A., 1909. Zur Benennung der Milchsäurebakterien. Centr. f. Bakteriol., II Abt., 24, 55-58.

[17] Hueppe, F., 1884. Untersuchungen über die Zersetzungen der Milch durch Microorganismen. Mitt. Kais. Gesundheitsamt, Berlin, 2, 309-371.

[18] Marpmann, G., 1886. Ueber die Erreger der Milchsäure-Gährung. Erganzungshefte Centralbl. f. allgem. Gesundheitspflege, Bd. 2, H 2, 117-132.

[19] Grotenfelt, G., 1889. Studien über die ersetzungen der Mileh. Fortschr. d. Med. $7,121-135$.

[20] Zopf, W., I885. Die Spaltpilze, Breslau : 3 Aufl., VII et 174 pp.

[21] Günter, C., et Thierfelder, H., 1895. Bacteriologische Untersuchungen über die spontane Milchgerinnung. Arch. f. Hyg., 25, 164-195.

[22] Lehmann, K. B, et Neumann, R. O., 1896. Bakteriologische Diagnostik, 2 vols. 1st ed. J. F. Lehmann's Verlag, Munich.

[23] Leichmann, G., 1896. ber die freiwillige Säuerung der Mileh. Ceniralbl. $f$. Bakteriol., II Abt. 2, 777-780.

[24] Kozai, Y., 1899. Beiträge zur Kenntniss der spontanen Milchgerinnung. Ztschr. f. Hyg. u. Infelktionskrankh, 31, 337-380.

[25] Beijerinck, M. W., 1901. Sur les ferrments lactiques de l'industrie. Arch. néerl. d. Sc. exact. et nat. Haarlem. Sér. 2, I, 212-243.

[26] Kruse, W., 1903. Das Verhältnis der Milchsäuerebakterien zum Streptococeus lanceolatus (Pneumoniecoceus, Enterococeus, u. s. w.). Centralbl. $f$. Bakteriol. I Abt. 34, 737-739.

[27] Hölling, 1904. Inaugural dissertation. Bonn.

[28] Heineman, P. G.,

a) 1906. The significance of streptococei in milk. Jour. Infec. Dis. 3, 173-182.

b) 1907. The Pathogenicity of S. lacticus. Jour. Infec. Dis, 4, 87-92.

c) 1919. Milk. W. B. Saunders Co.; Philadelphia, p. 347.

[29] Löhnis, F., 1907. Versuch einer Gruppierung der Milchsäurebakterien. Centralbl. $f$. Bakteriol. II Abt., 18, 97-149.

[30] Orla-Jensen, S., 1919. The lactie acid bacteria. Mém. de l'Acad. Roy. de Sci. et de Lettres de Danemark, Copenhague, Sect. d. Sci., $8^{\text {e }}$ sér. 5 (No.2), $81-196,51 \mathrm{pl}$.

[31] Weigmann, H., 1908. Pure ferments in the manufacture of butter. Industr. Lait. (Paris) 33, 2 pp., 18-19.

[32] Storch, V., 1919. Forstatte Undersogelser over Fremstillingen of Syre. 
vaekkere. 102de Beretning fra Forsogslaboratoriet. Kgl Veterinaer-og Landbohoiskoles Laboratorium for Landokonom:ske Forsog. Kobenhavn.

[33] Boekhout, F. W. J., 1919 Vereeniging tot Exploitatie einer Proetzuivelboerderg te Hoorn. Verslag over det jaar. 1919.

[34] Hammer, B. W., et Bailey, D. E., 1919. The volatile acid production of starters and of organisms isolated from them. Iowa Agr. Exp. Sta. Res. Bul. 55.

[35] Boekhout, F. W. J., et Ott de Vries, J. J., 1919. Aromabildner bei der Rahmsäuerung. Centralbl. f. Bakt. II Abt., 49, 373-382.

[36] Hammer, B. W., 1920. Volatile acid production of $S$. lacticus and the organisms associated with it in starters. Iowa Agr. Exp. Sta. Res. Bul. 63.

[37] Hammer, B. W., 1920. The type of lactic acid produced by starters and by organisms isolated from them. Iowa Agr. Exp. Sta. Res. Bul. 65 .

[38] Ayers, S. Henry, and Mudge, Cortland S., 1921. The organisms of a commercial lactic starter. Jour. Dairy Sci, 4, p. 240-249.

[39] Orla-Jeansen, S., and Orla-Jensen, A. D., and Spur, Bernhard, 1926. The butter aroma bacteria. Jour, Bact. 12, 333-342.

[40] Soncke Knudsen et Sorensen, A., 1929. Bidrag Til Syrevaekkernes Bacteriologi. (Contributions to the Bacteriology of Starters.) $\mathrm{Kgl}$. Veterinaer-og Landbohojskole Aarsskrift, 1929, 64-138. Kobenhavn.

[41] Hucker, G. J., 1928. Studies on the Coccaceae. XIV. Certain biochemical reactions produced by the streptococci. New York State Agric. Exp. Sta. Tech. Bul. 143, p. 3-64.

[42] Hueker, G. J., et Pederson, C. S., 1930. Studies on the Coccaceae. XVII. The genus Leuconostoc. N.Y. State Agr. Exp. Sta. Tech. Bul. 156.

[43] Cienkowski, L., 1878. Die Gallertbildungen des Zuckerrübensaftes, Charkow. 1879.

[44] von Freudenreich, E., 1897. Bacteriologische Untersuchungen über den Kefir. Centralbl. f. Bakteriol. II Abt. 3, 87-95.

[45] Migula, W., 1900. System der Bakterien. Jena II., 1068 pp.

[46] Beijerinck, M. W., 1912. Die durch Bakterien aus Rohrzucker erzeugten schleimigen Wandstoffe. Folia microbiologica Delft, 1, 377-408. Also in Verzamelde Geschriften van M. W. Beijerinck. Vol. 5, 89-110, 1922.

[47] Barthel, C., et Sadler, W., 1928. The casein-splitting abillity of dairy starters. (Trans. title). Meddel. Centralanst. f. försöksv. jordbruksomrädet (Sweden) No. 343, p. 9.

[48] Hucker, G. J., et Marquardt, J. C., 1926. The effect of certain lactic acid producing streptococci upon the flavor of cheddar cheese. N.Y. State Agr. Exp. Sta. Tech. Bul. 117, p. 3-13.

[49] Larson, C., and White, D., 1910. Milk powder starters in ereameries. South Dakota Agr. Exp. Sta. Bul. 123.

[50] Bouska, F. W., 1909. The use of starters in butter making. Iowa Agr. Exp. Sta. Res, Bul. 103, p. 217-229.

[51] Hammer, B. W., Sherwood, F. H., 1923. The volatile acids produced by starters and by organisms isolated from them. Iowa Agr. Exp. Sta. Res. Bul. 80.

[52] Templeton, Hugh L., and Sommer, H. H., 1929. The use of eitric acid and sodium citrate in starter eultures. Jour. Dairy Sci., 12, p. 21-36. 
[53] Orla-Jensen, S., et Orla-Jensen, A. D., et Spur, Bernhard, 1926. Les bactéries d'arome du beurre. Le Lait, 6, p. 161-169.

[54] Soncke Knudsen, 1926. Undersogelser over Syrevaekkere. Maelkeritidende, - No. 14, p. 235.

[55] Soncke Knudsen et Sorensen, A., 1927. Uber Milch als Nahrboden für gewisse Milchsäurebakterien. Centralbl. f. Bakteriol. II Abt. 71, 500-507.

[57] Soncke Knudsen, 1931. Starters. (Translated by E. R. Hiscox). The Journal of Dairy Research. 2, 137-161.

[58] Hansén, P. Arne, 1931. Lactic acid bacteria and the ripening of cream. F'estschrift in honor of Professor S. Orla-Jensen, pp. 26-30. The Danish Starter Laboratory, Odense.

\title{
DOCUMENTS ET INFORMATIONS
}

\section{UNE BRÈVE ÉTUDE DE L'INDUSTRIE DE LA LAITERIE AUX ÉTATS-UNIS D'AMÉRIQUE (1)}

\author{
par \\ T. MOJONNIER \\ de Chicago, Illinois (Etats-Unis de l'Amérique du Nord).

\section{INTRODUCTION.}

Il m'a été très agréable de faire cette brève revue pour le volume jubilaire en l'honneur du Professeur Ch. Porcher, entouré d'une si grande estime aux Etats-Unis. Comme elle a pour but de donner aux lecteurs du volume un exposé des faits les plus essentiels de l'industrie de la laiterie, aux Etats-Unis, j'ai essayé d'obtenir les renseignements les plus récents et les plus sûrs concernant ses divers aspects. Je tiens à mentionner que pour assembler les renseignements fournis, j'ai pu compter sur l'aide précieuse de différents amis que j'ai dans l'industrie de la laiterie, notamment : M. T. R. Pirtue, du Ministère de l'Agriculture des Etats-Unis, Washington, D.C., M. Fred. RASmussen, secrétaire de l'« International Association of Ice Cream Manufacturers ", le docteur Frank E. RICE, secrétaire de l'" Evaporated Milk Association ", MM. Roud MoCANN, directeur de l'" Ameri- can Dry Milk Institute ", M. R. E. Litrue, secrétaire de l'« International Association of Milk Dearlers "), et que j'ai consulté de nombreuses publications des Gouvernements de la Fédération et des Etats.

IMPORTANCE DE L'INDUSTRIE.

L'industrie laitière occupe une place des plus importantes dans la vie économique de la nation. Elle se place au premier rang, par les

(1) Paru dans le Volume jubilaire du Professeur Ch. Porcher. 